\title{
Comparison of Effect of Intrathecal Fentanyl-bupivacaine and Tramadol-bupivacaine Combination on Postoperative Analgesia in Lower Abdominal Surgeries
}

\author{
${ }^{1}$ Naina P Dalvi, ${ }^{2}$ Narendra Patil
}

\begin{abstract}
Introduction: This single-center, prospective, randomized, double-blind study compares the effect of intrathecal fentanylbupivacaine and tramadol-bupivacaine on the onset and duration of sensory and motor blockade, as well as postoperative analgesia in lower abdominal surgeries.
\end{abstract}

Materials and methods: Patients of either sex, aged 18 to 60 years, American Society of Anesthesiologists (ASA) grade I/II undergoing lower abdominal surgeries like appendicectomy, inguinal hernia repair surgery, and hydrocele surgery were administered either $2.5 \mathrm{~mL}$ of $0.5 \%$ bupivacaine $+0.5 \mathrm{~mL}(25 \mu \mathrm{g})$ of fentanyl citrate (group F) or $2.5 \mathrm{~mL}$ of $0.5 \%$ bupivacaine $+0.5 \mathrm{~mL}(25 \mathrm{mg}$ ) of tramadol (group T) intrathecally.

Monitoring of the vital parameters, onset and duration of sensory and motor block, duration of postoperative analgesia, visual analog scale (VAS) score, sedation score, and any adverse drug reactions was done at predetermined intervals.

Results: Sixty patients were randomized to the group $F(n=30)$ and group $T(n=30)$. The duration of sensory blockade was significantly prolonged in group $\mathrm{F}(314.66 \pm 49.25$ minutes $)$ as compared to group T (261.66 \pm 27.92 minutes). Similarly, duration of motor blockade was longer in group $\mathrm{F}(263.66 \pm 40.97$ minutes) compared to group $\mathrm{T}(214.66 \pm 26.61$ minutes $)$. The total duration of analgesia was significantly prolonged $(p<0.001)$ in group $F(412 \pm 97.888$ minutes $)$ compared to group $T$ (301 \pm 38.75 minutes).

Hemodynamic parameters, such as pulse, systolic blood pressure, diastolic blood pressure and oxygen saturation were comparable in both the groups. Visual analog scores were significantly lower in the group $\mathrm{F}$ patients as compared to the group $T$ patients. The group $F$ patients had got significantly higher sedation scores as compared to Group T patients.

Discussion: Fentanyl $25 \mu \mathrm{g}$, when added to $2.5 \mathrm{~mL}$ of $0.5 \%$ hyperbaric bupivacaine, confers prolonged duration of sensory

\footnotetext{
${ }^{1}$ Additional Professor, ${ }^{2}$ Ex-Resident

${ }^{1}$ Department of Anesthesia, HBT Medical College and Dr RN Cooper Municipal General Hospital, Mumbai, Maharashtra India

${ }^{2}$ Department of Anesthesia, Lokmanya Tilak Municipal General Hospital and Lokmanya Tilak Municipal Medical College, Mumbai, Maharashtra, India

Corresponding Author: Naina P Dalvi, Additional Professor Department of Anesthesia, HBT Medical College and Dr RN Cooper Municipal General Hospital, Mumbai, Maharashtra India, Phone: +919820711656, e-mail: drnaina@rediffmail.com
}

and motor blockade than $25 \mathrm{mg}$ tramadol added to $2.5 \mathrm{~mL}$ of $0.5 \%$ hyperbaric bupivacaine. The bupivacaine-fentanyl combination prolonged duration of sensory and motor blockade, improved analgesia, as manifested by lower pain scores, and prolonged duration of postoperative analgesia.

Keywords: Fentanyl, Intrathecal adjuvant, Postoperative analgesia, Tramadol.

How to cite this article: Dalvi NP, Patil N. Comparison of Effect of Intrathecal Fentanyl-bupivacaine and Tramadol-bupivacaine Combination on Postoperative Analgesia in Lower Abdominal Surgeries. Res Inno in Anesth 2016;1(2):35-40.

\section{Source of support: Nil}

Conflict of interest: None.

\section{INTRODUCTION}

Any expertise in anesthesia requires knowledge of pain relief during surgery and also into the postoperative period. The aim of postoperative pain relief is to provide comfort and to inhibit trauma-induced nociceptive impulses, thereby blunting autonomic and somatic reflex responses to pain.

Spinal anesthesia is a preferred method of anesthesia for surgery on lower half of body due to its efficacy, rapidity, reduction in blood loss, and protection against thromboembolic episodes. When the patient is receiving spinal anesthesia with local anesthetic agents like bupivacaine, addition of another drug intrathecally which will prolong analgesia is a logical choice. Predictably, thus a number of adjuvants have been added to spinal local anesthetics. ${ }^{1}$ Opioids like morphine, ${ }^{2}$ buprenorphine, ${ }^{3}$ pethidine, ${ }^{4}$ hydromorphone, ${ }^{5}$ diamorphine, ${ }^{6}$ fentanyl, ${ }^{7}$ sufentanil, ${ }^{8}$ and tramadol ${ }^{9}$ have been used for this purpose.

These opioids produce satisfactory analgesia for up to 24 hours postoperatively, but are frequently associated with side effects like respiratory depression, itching, nausea, vomiting, and urinary retention. Other adjuvants like clonidine, ${ }^{10}$ ketamine ${ }^{11}$ neostigmine, ${ }^{12}$ and midazolam ${ }^{13}$ have been tried, but none has become as popular as opioids in regular clinical practice.

The administration of opioids in combination with local anesthetics intrathecally is an excellent technique for managing postoperative pain following abdominal, pelvic, thoracic, or orthopedic procedures on lower 
extremities. We decided to compare effect of intrathecal fentanyl-bupivacaine and tramadol-bupivacaine combination in our present study and assess their effect on duration of sensory block, duration of motor block, and correlating it with duration of on postoperative analgesia in lower abdominal surgeries.

\section{MATERIALS AND METHODS}

After taking approval from the institution's ethics committee, written informed, valid consent was taken from all patients after explaining the study protocol. It was a single centre prospective randomized double blind comparative study.

A total of 60 patients of either sex - aged 18 to 60 years, American Society of Anesthesiologists (ASA) grade I/II, posted for lower abdominal surgeries like appendicectomy, inguinal hernia repair surgery, hydrocoele surgery - were included in the study. American Society of Anesthesiologists grade III and IV, pregnant and lactating mothers, patients with history of hypersensitivity to local anesthetic drugs, patients on chronic opioid therapy and opioid addicts, and patients on painmodifying drugs were excluded from the study.

Preanesthetic assessment included medical/surgical history; general/systemic examination; airway examination; and investigations, such as complete hemogram, bleeding time, and clotting time; chest X-ray; fasting blood sugar; and electrocardiogram for patients more than 35 years of age. Peripheral venous cannulation using $20 \mathrm{G} / 18 \mathrm{G}$ angiocath was done on dorsum of hand, and the patients were preloaded with Ringer's lactate $10 \mathrm{~mL} / \mathrm{kg}$. All patients were premedicated with injection glycopyrrolate $0.004 \mathrm{mg} / \mathrm{kg}$, injection ranitidine $1 \mathrm{mg} / \mathrm{kg}$, and injection ondansetron $0.008 \mathrm{mg} / \mathrm{kg}$.

Monitors including blood pressure cuff, cardioscope, and pulse oximeter were attached to patients. Baseline hemodynamics like pulse, blood pressure, oxygen saturation, and respiratory rate were noted.

All selected patients were made familiar with visual analog scale for grading of postoperative pain intensity. Patients were randomly divided into two groups of 30 each, using computerized randomization table in a double-blind manner.

Group bupivacaine-fentanyl (group F) received $2.5 \mathrm{~mL}$ of $0.5 \%$ bupivacaine $+0.5 \mathrm{~mL}(25 \mu \mathrm{g})$ of fentanyl citrate, whereas group bupivacaine-tramadol (group $\mathrm{T}$ ) received $2.5 \mathrm{~mL}$ of $0.5 \%$ bupivacaine $+0.5 \mathrm{~mL}$ ( $25 \mathrm{mg}$ ) of tramadol intrathecally.

Vital parameters like pulse, blood pressure, oxygen saturation, respiratory rate along with sensory and motor blockade, pain scores (visual analog scale, VAS) 4, and sedation scores (Ramsay sedation scores) 5 were checked every minute for the first 5 minutes, every 5 minutes for the next 15 minutes, and every 10 minutes thereafter, till the end of procedure.

Duration of surgery was noted at the end of surgery. No prophylactic pain relief was given. Patients were transferred to postoperative anesthesia care unit, and monitoring was continued for vital parameters.

Sedation score, level of sensory blockade, motor blockade, and VAS score were noted every 15 minutes for first 2 hours, every 30 minutes for next 4 hours, and thereafter at 2-hour interval for 24 hours.

Duration of analgesia was considered as interval from time of intrathecal injection to the time of rescue analgesic demanded postoperatively or when VAS score was more than 4 . Injection diclofenac $1.5 \mathrm{mg} / \mathrm{kg}$ intramuscularly was used as a rescue analgesic.

The total number of analgesic doses in the first 24 hours was noted.

Adverse effects like hypotension, bradycardia, nausea, vomiting, respiratory depression, excessive sedation, pruritus, urinary retention, and postdural puncture headache, if occurred, were noted. The patients were followed up postoperatively till he recovered completely from sensory and motor block and analgesia.

Statistical analyses were performed using SPSS software version 13. Data, such as age, height, weight, duration of surgery, onset of sensory and motor blockade, time required for peak sensory and motor blockade, duration of sensory and motor blockade, and duration of analgesia were analyzed with unpaired Student's t-test. Similarly, vital parameters like pulse, blood pressure, respiratory rate as well as sedation score and visual analog score were analyzed with unpaired Student's t-test. Data like age distribution, sex, type of surgery, ASA grade, the number of analgesics required in 24 hours, and peak sensory level achieved were analyzed with chi-square test. A value of $\mathrm{p}<0.05$ was considered as statistically significant. Scales like sedation and VAS scores were compared between groups using Mann-Whitney test.

\section{RESULTS}

Sixty patients were recruited in the two groups of 30 each randomly. Group bupivacaine-fentanyl (group F) received $2.5 \mathrm{~mL}$ of $0.5 \%$ bupivacaine $+0.5 \mathrm{~mL}(25 \mu \mathrm{g})$ of fentanyl citrate, whereas group bupivacaine-tramadol (group T) received $2.5 \mathrm{~mL}$ of $0.5 \%$ bupivacaine $+0.5 \mathrm{~mL}(25 \mathrm{mg})$ of tramadol intrathecally.

No statistically significant difference was found by applying unpaired t-test $(p>0.05)$ in the demographic data (Table 1). The onset of sensory blockade was comparable in group $\mathrm{F}$ (1.37 minutes) and group $\mathrm{T}$ 
Table 1: Demographic data

\begin{tabular}{llll}
\hline Parameter & Group $F(n=30)$ & Group $T(n=30)$ & $p$-value \\
\hline Age (years) & $33.23 \pm 9.031$ & $33 \pm 9.993$ & 0.925 \\
Sex ratio (M:F) & $22: 8$ & $22: 8$ & \\
Weight (kg) & $59.33 \pm 5.962$ & $60.47 \pm 4.447$ & 0.407 \\
Duration of & $90.17 \pm 18.684$ & $86.67 \pm 23.829$ & 0.529 \\
surgery (min) & & & \\
\hline
\end{tabular}

Table 2: Comparison of onset and duration of sensory and motor blockade

\begin{tabular}{lllllll}
\hline & \multicolumn{2}{c}{ Group $F$} & & \multicolumn{2}{c}{ Group $T$} & \\
\cline { 2 - 3 } & Mean & $\pm S D$ & & Mean & $\pm S D$ & p-value \\
\hline $\begin{array}{l}\text { Onset of sensory } \\
\text { blockade (min) }\end{array}$ & 1.37 & 0.556 & 1.47 & 0.507 & 0.47 \\
$\begin{array}{l}\text { Duration of sensory } \\
\text { blockade (min) }\end{array}$ & 314.66 & 49.25 & 261.66 & 27.92 & $<0.001$ \\
$\begin{array}{l}\text { Onset of motor } \\
\text { blockade (min) }\end{array}$ & 2.47 & 0.776 & 2.6 & 0.621 & 0.466 \\
$\begin{array}{l}\text { Duration of motor } \\
\text { blockade (min) }\end{array}$ & 263.66 & 40.97 & 214.66 & 26.61 & $<0.001$ \\
\hline
\end{tabular}

(1.47 minutes). Similarly, onset of motor blockade was comparable in group F (2.47 minutes) and group T (2.6 minutes). The duration of sensory blockade was prolonged in group $\mathrm{F}$ (314.66 minutes) as compared to group T (261.66 minutes). Similarly, the duration of motor blockade was prolonged in group F (263.66 minutes) as compared to group T (214.66 minutes). Statistically, significant difference was found by applying unpaired t-test $(\mathrm{p}<0.05)($ Table 2$)$.

Group F required rescue analgesia at 412 minutes while group $\mathrm{T}$ required it at 301.33 minute. Using unpaired $t$-test, this is statistically significant $(p<0.05)$ (Graph 1). The changes in visual analog score for pain were significant from $3 \frac{1}{2}$ hours onward up to $4 \frac{1}{2}$ hours. Visual analog score were low in group $\mathrm{F}$ as compared to group $\mathrm{T}$ (Graph 2).

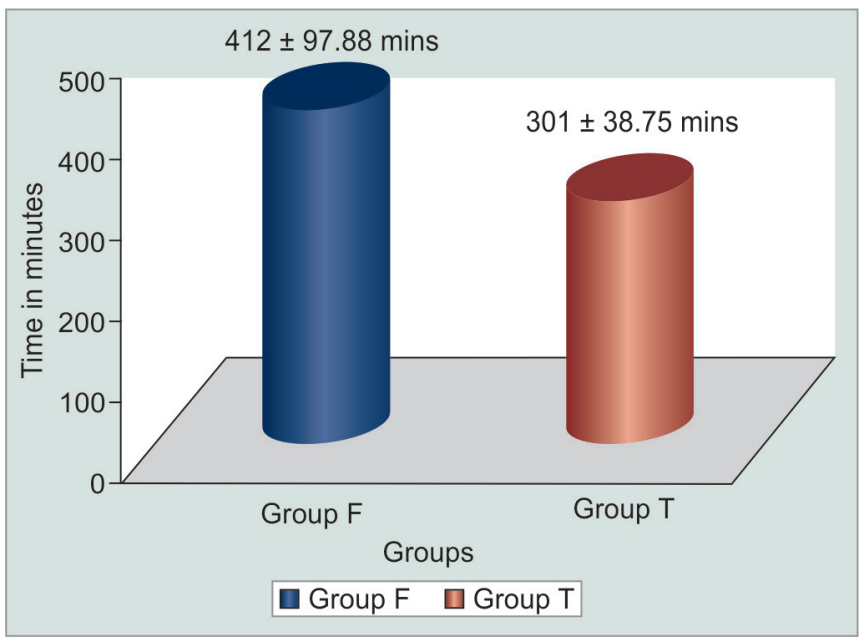

Graph 1: Comparison of duration of analgesia
Total analgesic requirement during the observation period of 24 hours was noted. Group F patients required fewer doses of analgesics as compared to group $\mathrm{T}$ (Table 3 ).

The baseline pulse rate and systolic blood pressure were comparable in both the groups. There was no statistically significant difference between the pulse rate and systolic pressure in both the groups throughout the observation period.

\section{DISCUSSION}

The aim of intraoperative and postoperative pain relief is to provide comfort and to inhibit trauma-induced nociceptive impulses, thereby blunting autonomic and somatic reflex responses to pain. Postoperative analgesia plays a pivotal role in medical practice, enabling faster restoration of physiological functions.

Spinal anesthesia is a popular anesthetic technique for surgeries on abdomen and lower limbs. Though subarachnoid block provides effective analgesia in the initial postoperative period, the effect is very short lasting. Hence, additional analgesics are needed to lengthen the duration of analgesia provided. The use of potent opioid analgesics systemically has been associated with respiratory depression, nausea, vomiting, itching, and urinary retention. Hence, attempts were made to increase the duration of analgesia produced by subarachnoid block by addition of various intrathecal adjuvants. Various opioids like morphine, ${ }^{2}$ buprenorphine, ${ }^{3}$ hydromorphone, ${ }^{5}$

Table 3: Total number of analgesics in 24 hours

\begin{tabular}{llllll}
\hline \multirow{2}{*}{$\begin{array}{l}\text { Total number of } \\
\text { analgesic in 24 hours }\end{array}$} & \multicolumn{2}{c}{ Group $F(n=30)$} & & \multicolumn{2}{c}{ Group $T(n=30)$} \\
\cline { 2 - 3 } \cline { 5 - 6 } & 12 & $\%$ & & $n$ & $\%$ \\
2 & 18 & 60 & & 18 & 60 \\
3 & 0 & 0 & 12 & 40 \\
\hline Total & 30 & 100 & 30 & 100 \\
\hline
\end{tabular}

Chi-square $=24.00 ; p<0.0001 ; p<0.05$ significant

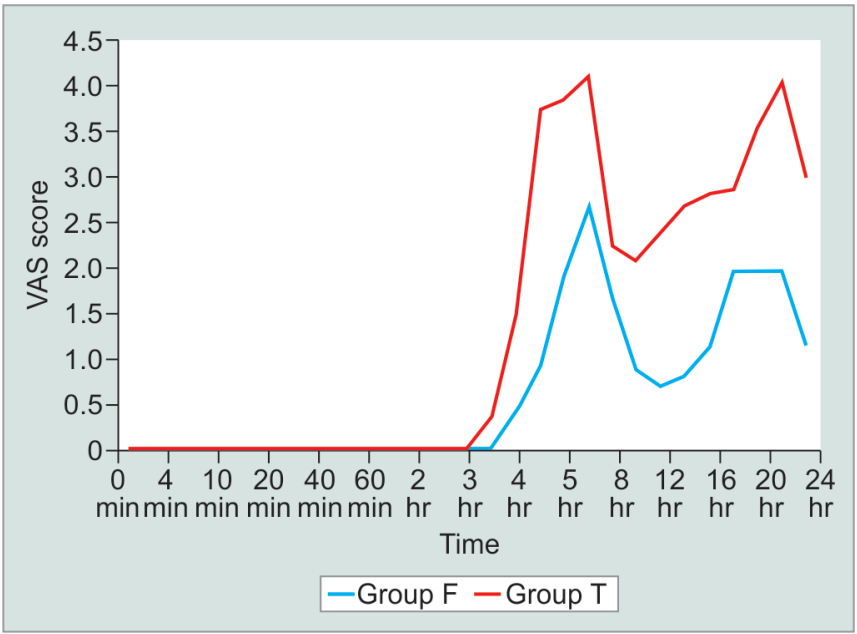

Graph 2: Visual analog scale monitoring 
fentanyl, ${ }^{7}$ sufentanil, ${ }^{7}$ tramadol $^{8}$ and nonopioid drugs clonidine, ${ }^{10}$ ketamine, ${ }^{11}$ neostigmine, ${ }^{12}$ and midazolam ${ }^{13}$ have been used as adjuvants.

Analgesic effect of opioids arises from their ability to inhibit the ascending transmission of nociceptive information from the dorsal horn of the spinal cord directly and to activate the pain control circuits that descend from the midbrain, via the rostral ventromedial medulla, to the dorsal horn of the spinal cord.

Fentanyl, a lipophilic opioid, is a strong $\mu$ and $\kappa$ receptor agonist and 100 times more potent than morphine as an analgesic. ${ }^{1}$ It acts on the $\mu$ receptors present in substantia gelatinosa of the dorsal horn of the spinal cord, causing inhibition of substance $P$ release which results in alteration of pain perception and inhibition of pain pathway. It does not tend to migrate to the fourth ventricle in sufficient concentration to cause delayed respiratory depression when administered intrathecally. ${ }^{14}$

Tramadol is a centrally acting opioid. It binds to the $\mu$-receptor and to a lesser extent to the $\delta$ - and $\kappa$-opioid receptors, but is 5 to 10 times less potent than morphine as an analgesic. ${ }^{15}$ It enhances the function of spinal descending inhibitory pathways by inhibition of neuronal reuptake of norepinephrine and serotonin as well as presynaptic stimulation of 5-hydroxytryptamine release. ${ }^{16}$ It has lower incidence of cardiovascular and respiratory depression as compared to other opioid agonists.

Biswas et $\mathrm{al}^{14}$ conducted a study to show that intrathecal fentanyl, when added to hyperbaric bupivacaine $(2 \mathrm{~mL}$ of $0.5 \%$ hyperbaric bupivacaine with $0.25 \mathrm{~mL}$, i.e., $12.5 \mu \mathrm{g}$ fentanyl), improves analgesia during cesarean delivery and in the early postoperative period. Chakraborty et $\mathrm{al}^{8}$ had undertaken a study to evaluate the duration of analgesia conferred by intrathecal tramadol added to hyperbaric bupivacaine $(3 \mathrm{~mL} 0.5 \%$ hyperbaric bupivacaine and $0.2 \mathrm{~mL}$, i.e., $20 \mathrm{mg}$ tramadol) in patients undergoing major gynecological surgery in a randomized double-blind placebo-controlled protocol. The duration of analgesia was prolonged with addition of tramadol.

Worldwide, many studies have been conducted on the intrathecal use of either fentanyl or tramadol in combination with local anesthetic agents, but there is not a single study available which has compared the intrathecal use of these two opioids in terms of efficacy and safety. So, this study was conducted to compare the two opioids, fentanyl and tramadol, when combined intrathecally with hyperbaric bupivacaine for postoperative analgesia.

The present study was a single-center, prospective, randomized, double-blind study. The patients were divided into two groups of 30 patients each. We have sought to compare the onset, duration, and analgesic effect of intrathecal fentanyl-bupivacaine with that of tramadol-bupivacaine. Group F received $2.5 \mathrm{~mL}$ of $0.5 \%$ hyperabaric bupivacaine with $0.5 \mathrm{~mL}(25 \mu \mathrm{g})$ of fentanyl while group T received $2.5 \mathrm{~mL}$ of $0.5 \%$ hyperbaric bupivacaine with $0.5 \mathrm{~mL}(25 \mathrm{mg})$ of tramadol. Mixing of these drugs did not show any physical changes like precipitation, turbidity, and changes in color.

In the present study, demographical parameters like age, sex, weight, height, and ratio of ASA were comparable between the fentanyl group and tramadol group. Likewise, duration of surgery and types of surgery in both the groups were comparable.

The effect of intrathecal fentanyl and tramadol in combination with hyperbaric bupivacaine on sensory parameters including onset with time for peak sensory block and duration of sensory block was compared.

It was found that the patients receiving fentanyl and tramadol had nearly the same onset of sensory block $(1.37 \pm 0.55$ and $1.47 \pm 0.51$ respectively), but fentanyl group attained the peak sensory level earlier $(3.77 \pm 0.72$ vs $5.13 \pm 0.77$ minutes) which is statistically significant. The duration of sensory blockade was found to be longer with intrathecal fentanyl than intrathecal tramadol (314.66 \pm 49.25 vs $261.66 \pm 27.92$ minutes respectively). Biswas et $\mathrm{al}^{14}$ and Ben-David et $\mathrm{al}^{17}$ found that the duration of sensory blockade was longer in the patients who received intrathecal bupivacaine with fentanyl than the patients who received intrathecal bupivacaine alone.

In our study, it was found that patients receiving fentanyl and tramadol had nearly the same onset of motor block $(2.47 \pm 0.777$ vs $2.6 \pm 0.62$ minutes $)$ and comparable time to achieve peak motor block $(6.57 \pm 1.135 \mathrm{vs}$ $7.03 \pm 1.066$ minutes). The duration of motor block was longer in group $\mathrm{F}$ as compared to group $\mathrm{T}$ and was statistically highly significant $(263.66 \pm 40.97$ vs $214.66 \pm 26.61$ minutes, $p<0.001)$. It implies that the motor recovery and street fitness was delayed in fentanyl group as compared to the tramadol group.

The duration of postoperative analgesia was found to be significantly prolonged in fentanyl group as compared to the tramadol group $(412 \pm 97.88$ vs $301.33 \pm 38.75$ minutes; $p<0.001)$. Clinically, it was also found that the patients from fentanyl group were more pain-free and comfortable than the tramadol group. Similar results have been obtained by Biswas et $\mathrm{a}^{14}$ and Ben-David et al. ${ }^{17}$ According to Dahlgren et $\mathrm{al}^{18}{ }^{18}$ intrathecal fentanylbupivacaine and sufentanil-bupivacaine had prolonged duration of analgesia as compared to the patients receiving intrathecal bupivacaine alone. Chakraborty et $\mathrm{al}^{8}$ found that the duration of postoperative analgesia was longer in the patients receiving intrathecal bupivacainetramadol than the patients receiving only bupivacaine. Parthasarathy and Ravishankar ${ }^{19}$ found that the duration of postoperative analgesia was significantly longer in the 
patients receiving intrathecal lignocaine-tramadol than in the patients receiving lignocaine only.

These results are consistent with experimental evidence of a synergistic interaction between spinal opioids and local anesthetics. ${ }^{20-24}$ This is due to separate mechanisms of action of both the drugs. Intrathecal opioids inhibit nociceptive afferent synaptic transmission via $A \delta$ and $C$ fibers by opening presynaptic potassium channels to inhibit transmitter release and thus reduce calcium influx. There is also a direct postsynaptic effect with hyperpolarization and reduced neuronal activity. ${ }^{25}$ Local anesthetics work primarily by causing blockade of voltage-gated sodium channels in the axonal membrane and, possibly, a further effect on presynaptic inhibition of calcium channels. ${ }^{26}$

The comparison of VAS scores between the groups showed that group $\mathrm{F}$ had significantly lower scores than group T. The significant difference in VAS scores was found from $3 \frac{1}{2}$ hours up to $4 \frac{1}{2}$ hours from the subarachnoid block. Three and half hours onward, the patients from tramadol group needed rescue analgesia steadily. Four and half hours onward, some patients from fentanyl group also started requiring rescue analgesia. Therefore, at 5 hours, the means of VAS of two groups became comparable and the difference in VAS scores became nonsignificant.

Injection diclofenac sodium $1.5 \mathrm{mg} / \mathrm{kg}$ was used as a rescue analgesic, and requirement of analgesics in 24 hours was monitored. In fentanyl group, 12 patients out of 30 required single analgesic dose whereas in tramadol group, all patients required more than 1 analgesic dose. Eighteen patients from both the groups required 2 doses of analgesic within 24 hours. No patient from group $\mathrm{F}$ required 3 doses of analgesic while 12 patients from group $T$ required 3 analgesic doses. The need for other systemic opioid or nonopioid analgesics was reduced and the side effects of them could be averted. Thus, it can be inferred that intrathecal fentanyl added to hyperbaric bupivacaine provides better quality of postoperative analgesia.

In a recent study, Subedi et $\mathrm{al}^{27}$ demonstrated that for cesarean section under subarachnoid block with hyperbaric bupivacaine, intrathecal tramadol $10 \mathrm{mg}$ produces a longer duration of pain relief with a lower incidence of shivering compared to intrathecal fentanyl $10 \mathrm{mg}$. Afolayan et $\mathrm{al}^{28}$ demonstrated that intrathecal tramadol $25 \mathrm{mg}$ is equipotent with $25 \mu \mathrm{g}$ of intrathecal fentanyl during bupivacaine subarachnoid block for appendicectomy. Singh ${ }^{29}$ compared bupivacaine with bupivacainetramadol and bupivacaine-fentanyl and found that duration of analgesia is prolonged with both tramadol and fentanyl, but is more prolonged with fentanyl.

Hemodynamic parameters, such as pulse rate and oxygen saturation were comparable in both the groups. The difference of the systolic and diastolic blood pressures between fentanyl group and tramadol groups was not significant. In both the groups, the systolic and diastolic blood pressures dropped till 40 to 50 minutes and then it steadily increased over the time. No episode of hypotension occurred. The patients did well throughout the observation period. No patient required injection ephedrine for the treatment of hypotension.

All the patients were calm, sleeping comfortably, and responding to verbal commands. Patients from fentanyl group were more sedated than the patients from tramadol group. No patient had any evidence of delayed respiratory depression or hypoxia in both the groups. Biswas et $\mathrm{al}^{14}$ in their study found that there was no respiratory depression or hypoxia in the patients receiving intrathecal fentanyl and intrathecal bupivacaine alone. Chakraborty et $\mathrm{al}^{8}$ found that there was no consequent respiratory depression in the patients receiving intrathecal tramadol and intrathecal bupivacaine alone. Though fentanyl and tramadol act on $\mu$ receptors, as fentanyl is more lipophilic, it ascends higher than tramadol and causes more sedation. ${ }^{1}$ No patient experienced airway compromise or required airway assistance.

All the patients were monitored in the intraoperative and postoperative period for opioid-related side effects. Seven patients from fentanyl group and 14 patients from tramadol group experienced nausea while 3 patients from fentanyl group and 11 patients from tramadol group experienced vomiting. Eleven out of 30 patients complained of pruritus from the fentanyl group. There were no neurological and urological complications noted in the observation period. This finding is supported by Dahlgren et al. ${ }^{18}$

\section{CONCLUSION}

Fentanyl $25 \mu \mathrm{g}$, when added to $2.5 \mathrm{~mL}$ of $0.5 \%$ hyperbaric bupivacaine, confers prolonged duration of sensory and motor blockade than $25 \mathrm{mg}$ tramadol added to $2.5 \mathrm{~mL}$ of $0.5 \%$ hyperbaric bupivacaine. There was no difference in the onset of sensory and motor blockade. The bupivacaine-fentanyl combination prolonged duration of sensory and motor blockade, improved analgesia, as manifested by lower pain scores, and prolonged duration of postoperative analgesia.

\section{ACKNOWLEDGMENTS}

Authors would like to thank Dr SA Kamath, Dean, Lokmanya Tilak Municipal General Hospital and Lokmanya Tilak Municipal Medical College, Sion, Mumbai, for allowing us to this study.

\section{REFERENCES}

1. Brown DL. Spinal, epidural and caudal anesthesia. In: Miller RD, editor. Miller's anesthesia. 7th ed. Vol. 2. Philadelphia (PA): Churchill Livingstone; 2010. p. 1611-1638. 
2. Wang JK, Nauss LA, Thomas JE. Pain relief by intrathecally applied morphine in man. Anesthesiology 1979 Feb;50(2):149-151.

3. Dixit S. Postoperative analgesia after caesarean section: an experience with intrathecal buprenorphine. Indian J Anaesth 2007;51(6):515-518.

4. Pandya ST. Labour analgesia: recent advances. Indian J Anaesth 2010 Sep-Oct:54(5):400-408.

5. Tejswani GA, Rattan AK. The role of spinal opioid receptors in antinociceptive effects produced by intrathecal administration of hydromorphone and buprenorphine in the rat. Anesth Analg 2002 Jun;94(6):1542-1546.

6. Cowan CM, Kendall. JB, Barclay PM, Wilkes RG. Comparison of intrathecal fentanyl and diamorphine in addition to bupivacaine for caesarean section under spinal anaesthesia. Br J Anaesth 2002 Sep;89(3):452-458.

7. Fournier R, Gessel EV, Weber A, Gamulin Z. A comparison of intrathecal analgesia with fentanyl or sufentanil after total hip replacement. Anesth Analg 2000 Apr;90(4):918-922.

8. Chakraborty S, Chakrabarti J, Bhattacharya D. Intrathecal tramadol added to bupivacaine as spinal anesthetic increases analgesic effect of the spinal blockade after major gynecological surgeries. Indian J Pharmacol 2008 Aug;40(4):180-182.

9. Cann CC, editor. Principles of anesthesiology: general and regional anesthesia. 3rd ed. Pennsylvania (PA): Lea and Febiger; 1993. p. 1445-1554

10. Chaturvedi S, Chaturvedi A. Postoperative pain and its management. Indian J Crit Care Med 2007;11(4):204-211.

11. Bhattacharya D, Banerjee A. A comparative study of clinical effects of intrathecal hyperbaric bupivacaine and ketamine in hyperbaric solution. Indian J Anaesth 2004;48(2):116-120.

12. Klamt JG, Slullitel A, Garcia IV, Prado WA. Postoperative effect of intrathecal neostigmine and its influence on spinal anaesthesia. Anaesthesia 1997 Jun;52(6):547-551.

13. Batra YK, Jain K. Addition of intrathecal midazolam to bupivacaine produces better postoperative analgesia without prolonging recovery. Int J Clin Pharmacol Ther 1999 Oct;37(10): 519-527.

14. Biswas BN, Rudra A, Bose BK, Nath S, Chakrabarty S, Bhattacharjee S. Intrathecal fentanyl with hyperbaric bupivacaine improves analgesia during caesarean delivery and in early postoperative period. Indian J Anaesth 2002;46(6): 469-472.

15. Fukuda K. Opioids. In: Miller RD, editor. Miller's anesthesia. 7th ed. Philadelphia (PA): Churchill Livingstone Elsevier; 2007. p. 769-824.

16. Stoelting RK, Hiller SC. Opioids agonists and antagonists. In: Brown B, Murphy F, editors. Pharmacology and physiology in anesthetic practice. 4th ed. Philadelphia (PA): Lippincott Williams and Wilkins; 2006. p. 87-126.

17. Ben-David B, Solomon E, Levin H, Admoni H, Goldik Z. Intrathecal fentanyl with small-dose dilute bupivacaine: better anesthesia without prolonging recovery. Anesth Analg 1997 Sep;85(3):560-565.

18. Dahlgren G, Hultstrand C, Jakobsson J, Norman M, Eriksson EW, Martin H. Intrathecal sufentanil, fentanyl or placebo added to bupivacaine for caesarean section. Anesth Analg 1997 Dec;85(6):1288-1293.

19. Parthasarathy S, Ravishankar M. Single dose intrathecal tramadol in the management of postappendicectomy pain. J Anaesth Clin Pharmacol 2002;18(4):419-422.

20. Maves TJ, Gebhart GF. Antinociceptive synergy between intrathecal morphine and lidocaine during visceral and somatic nociception in the rat. Anesthesiology 1992 Jan;76(1): 91-99.

21. Tejwani GA, Rattan AK, McDonald JS. Role of spinal opioid receptors in the antinociceptive interactions between intrathecal morphine and bupivacaine. Anesth Analg 1992 May;74(5):726-734.

22. Akerman B, Arwestrom E, Post C. Local anesthetics potentiate spinal morphine antinociception. Anesth Analg 1988 Oct; 67(10):943-948.

23. Wang C, Chakrabarti MK, Whitman JG. Specific enhancement by fentanyl of the effects of intrathecal bupivacaine on nociceptive afferent but not on sympathetic efferent pathways in dogs. Anesthesiology 1993 Oct;79(4):766-773.

24. Penning JP, Yaksh TL. Interaction of intrathecal morphine with bupivacaine and lidocaine in the rat. Anesthesiology 1992 Dec;77(6):1186-2000.

25. Dickenson AH. Mechanisms of the analgesic actions of opiates and opiods. Br Med Bull 1991 Jul;47(3):690-702.

26. Butterworth JF, Strichartz GR. Molecular mechanisms of local anesthesia: a review. Anesthesiology 1990 Apr;72(4):711-734.

27. Subedi A, Biswas BK, Tripathi M, Bhattarai BK, Pokharela K. Analgesic e ects of intrathecal tramadol in patients undergoing caesarean section: A randomised, double-blind study. Int J Obstet Anesth 2013 Nov; 22(4):316-321.

28. Afolayan JM, Olajumoke TO, Amadasun FE, Edomwonyi NP. Intrathecal tramadol versus intrathecal fentanyl for visceral pain control during bupivacaine subarachnoid block for open appendicectomy. Niger J Clin Pract 2014 May-Jun; 17(3):324-330.

29. Singh AP. A comparative study of intrathecal bupivacaine with bupivacainetramadol and bupivacaine-fentanyl for postoperative pain relief in lower abdominal and lower limb surgeries. Int J Pharm Bio Sci 2015 Oct;6(4):752-758. 